\title{
ARGILAS BENTONÍTICAS DA PENÍNSULA DE SANTA ELENA, EQUADOR: PILARIZAÇÃo, ATIVAÇÃo ÁCIDA E SEU USO COMO DESCOLORANTE DE ÓLEO DE SOJA
}

\author{
Ana M. Morales-Carrera* \\ Departamento de Geologia, Escola de Minas, Universidade Federal de Ouro Preto, Campus Universitário, s/n, 35400-000 Ouro \\ Preto - MG, Brasil / Facultad de Ciencias de la Tierra, Escuela Superior Politécnica del Litoral, Campus Gustavo Galindo, km \\ 30.5 vía Perimetral. Guayaquil, Ecuador \\ Angélica F. D. C.Varajão \\ Departamento de Geologia, Escola de Minas, Universidade Federal de Ouro Preto, Campus Universitário, s/n, 35400-000 Ouro \\ Preto - MG, Brasil \\ Marcos A. Gonçalves e Antônia S. Stachissini \\ Departamento de Química, Instituto de Ciências Exatas e Biológicas, Universidade Federal de Ouro Preto, Campus \\ Universitário, s/n, 35400-000 Ouro Preto - MG, Brasil \\ Recebido em 11/9/08; aceito em 27/5/09; publicado na web em 10/11/09

\begin{abstract}
BENTONITIC CLAYS OF SANTA ELENA PENÍNSULA, ECUADOR: AL-PILARIZATION, ACID-ACTIVATION AND ITS USE IN THE BLEACHING OF SOYBEAN OIL. Two samples of calcic bentonite of the Santa Elena Peninsula, Ecuador, were pillared with $\mathrm{Al}_{13}$ ions in the ratio of 10,15 and 20 meq of $\mathrm{Al} \mathrm{g}^{-1}$ of clay, calcinated at 573,723 and $873{ }^{\circ} \mathrm{K}$ and acid activated with 4,6 and $8 \mathrm{~mol} \mathrm{~L}^{-1} \mathrm{H}_{2} \mathrm{SO}_{4}$. Analyses by X-ray diffraction, X-ray fluorescence, differential and gravimetric thermal, density, surface area and porosity, were applied in order to study the modifications occurred in the crystalline structure of the montmorillonite. The $8 \mathrm{~mol} \mathrm{~L}^{-1}$ $\mathrm{H}_{2} \mathrm{SO}_{4}$ acid-activated 15 meq of $\mathrm{Al} \mathrm{g}^{-1}$ of clay at $573{ }^{\circ} \mathrm{K}$ Al-pillared samples indicated the best results in the bleaching of the soybean oil measured by UV-visible spectrophotometer.
\end{abstract}

Keywords: Al-pillared bentonite; acid-activated bentonite; bleaching capacity.

\section{INTRODUÇÃO}

A eficiência dos argilominerais nos processos catalíticos e de adsorção é aumentada através de modificações estruturais obtidas por ativação ácida, intercalação e pilarização. Ativação ácida é geralmente realizada através do tratamento com ácido clorídrico ou ácido sulfúrico e tem como objetivos eliminar impurezas cimentantes adsorvidas naturalmente nos cristais, substituir cátions trocáveis por $\mathrm{H}^{+}$, abrir as bordas dos cristais e lixiviar cátions octaédricos, como $\mathrm{Al}^{+3} \mathrm{e} \mathrm{Mg}^{+2}$. Este tratamento garante maior dispersão das partículas com consequente aumento da área superficial específica, aumento da porosidade aberta e diâmetro dos poros. $\mathrm{O}$ grau de cristalinidade das esmectitas reduz com a ativação ácida, ocorrendo inicialmente um aumento na área superficial e, depois, uma diminuição com a continuação do tratamento. ${ }^{1} \mathrm{O}$ aumento da capacidade de adsorção das esmectitas com o tratamento ácido é principalmente devido ao aumento da acidez de Brönsted. Os grãos da argila tornam-se doadores de prótons ${ }^{2} \mathrm{H}^{+}$.

Argilas pilarizadas, também conhecidas como PILC (Pillared Interlayer Clay), são materiais com uma estrutura cristalina porosa permanente, com grande superfície específica, propriedades ácidas e, estáveis termicamente. ${ }^{3}$ A porosidade permanente é obtida pela intercalação de polioxicátions que, após tratamento térmico, formam uma galeria de "pilares" entre as camadas estruturais dos argilominerais. ${ }^{4}$

Na vasta literatura sobre argilas pilarizadas, um dos primeiros trabalhos sobre intercalação de íons ${ }^{4}$ utilizou íons metálicos de $\mathrm{Al}, \mathrm{Zr}$, Ti de maneira individual ou como uma combinação destes para a pilarização de argilas esmectíticas. Outros trabalhos foram feitos utilizando íons metálicos de maneira individual para obter sítios catalíticos específicos, tais como Ni, ${ }^{5} \mathrm{Si},{ }^{6} \mathrm{Al}, \mathrm{Cr}, \mathrm{Fe}, \mathrm{Ti}, \mathrm{Zr},{ }^{7} \mathrm{Cu}, \mathrm{Zr},{ }^{8} \mathrm{Ce}, \mathrm{La},{ }^{9} \mathrm{Ta},{ }^{10} \mathrm{~Pa} .{ }^{11}$

$\mathrm{O}$ íon de Keggin $\left(\left[\mathrm{Al}_{13} \mathrm{O}_{4}(\mathrm{OH})_{24}\left(\mathrm{H}_{2} \mathrm{O}\right)_{12}\right]^{7+}\right)$, também conhecido

*e-mail: anamc73@yahoo.com como $\mathrm{Al}_{13}$ é o cátion mais utilizado em pilarização. A montmorilonita é o argilomineral mais utilizado nas intercalações e pilarizações devido principalmente a sua abundância, relativa alta capacidade de troca de cátions e alta superfície específica. ${ }^{12}$

O íon de Keggin é obtido a partir de soluções contendo polioxocátions de alumínio. Estas soluções são preparadas pela hidrólise de um sal de alumínio, tipo $\mathrm{AlCl}_{3}$, e posteriormente neutralizadas com hidróxido de sódio até uma razão $[\mathrm{OH}] /[\mathrm{Al}]$ entre 1,8 e 2,4. ${ }^{13}$ Este íon é intercalado entre as camadas da montmorilonita através do processo de troca iônica com os cátions interlamelares compensadores de carga, como o $\mathrm{Ca}^{+2}$. A posterior calcinação do compósito intercalado, em temperaturas entre 473 e $973{ }^{\circ} \mathrm{K}$, produz a desidroxilação do íon $\mathrm{Al}_{13}$ resultando em aglomerados de $\mathrm{Al}_{2} \mathrm{O}_{3}$ que atuam como pilares mantendo a estrutura da montmorilonita rígida e aberta, conferindo maior porosidade à estrutura. ${ }^{4}$ $\mathrm{O}$ processo de pilarização confere acidez de Lewis à argila porque o alumínio dos pilares exibe estados de coordenação incompletos e atuam como receptores de elétrons. ${ }^{2}$

A força ácida do material depende do tipo de cátions, da sua posição na superfície e da temperatura do tratamento térmico. Até em torno de $573^{\circ} \mathrm{K}$, as argilas ativadas com ácidos e pilarizadas contêm sítios ácidos de Brönsted e Lewis. ${ }^{14}$ Uma importante fonte de prótons (acidez de Brönsted) é a reação de desidratação do cátion $\mathrm{Al}_{13}$ :

$$
2\left[\mathrm{Al}_{13} \mathrm{O}_{4}(\mathrm{OH})_{24}\left(\mathrm{H}_{2} \mathrm{O}\right)_{12}\right]^{+7}=13 \mathrm{Al}_{2} \mathrm{O}_{3}+17 \mathrm{H}_{2} \mathrm{O}+14 \mathrm{H}^{+}
$$

Com aquecimento e consequente eliminação de água a acidez de Lewis aumenta, entretanto a acidez de Brönsted decresce porque o aumento da mobilidade protônica provoca a migração dos $\mathrm{H}^{+}$através da folha octaédrica e compensa a carga negativa líquida dos cristais. Isto resulta na diminuição da CTC do argilomineral (decréscimo de $\cong 90 \%$ ) e na inacessibilidade dos prótons trocáveis $\mathrm{H}^{+}$(acidez de Brönsted). Uma nova ativação ácida após a pilarização aumenta a acidez de Brönsted 
novamente porque ocorre a protonação dos hidróxidos superficiais e dos pilares, $\mathrm{M}_{\mathrm{x}}(\mathrm{OH})_{\mathrm{y}}$, que transformam em $\mathrm{M}_{\mathrm{x}}(\mathrm{OH})_{\mathrm{y}} \mathrm{zH}^{+}$como $\mathrm{Al}(\mathrm{OH})_{3} \mathrm{H}^{+}$.

A adsorção de clorofila depende da acidez de Brönsted das argilas. $\mathrm{Al}^{3+}$ e Ti ${ }^{4+}$ podem incrementar a acidez de Brönsted, enquanto que $\mathrm{Na}^{+}$ pode ter um efeito contrário. ${ }^{15}$

Baseado nas propriedades de adsorção das argilas, alguns autores ${ }^{2,16}$ estudaram argilas ativadas com $\mathrm{H}_{2} \mathrm{SO}_{4}$ e pilarizadas com $\mathrm{Al}_{13}$ depois de ativadas com $\mathrm{H}_{2} \mathrm{SO}_{4}$, no descoloramento de óleo de semente de algodão. Argilas pilarizadas com $\mathrm{Al}_{13}$ mostraram-se mais eficientes no descoloramento do óleo do que argilas pilarizadas com $\mathrm{Al}_{13}$ após ativação ácida e do que argilas somente ativadas. ${ }^{16}$ Entretanto, outras amostras ativadas após pilarizadas mostraram maior eficiência do que as amostras pilarizadas, porém, não superaram a argila descolorante comercial, Tonsil. ${ }^{2}$ No descoloramento de óleo de canola com argila montmorilonítica cálcica pilarizada com alumínio após ativação ácida com $\mathrm{H}_{2} \mathrm{SO}_{4}$, conseguiu-se entre 70 e $99 \%$ de adsorção de clorofila. ${ }^{17}$

Bentonitas ativadas são amplamente utilizadas no refino de óleos minerais, vegetais e animais, sendo suas funções desodorizar, desidratar, neutralizar e/ou descolorir. ${ }^{18} \mathrm{~A}$ ativação com $\mathrm{H}_{2} \mathrm{SO}_{4}$ é bastante utilizada em materiais argilosos ricos em montmorilonita. ${ }^{19-25} \mathrm{~A}$ ativação ácida de montmorilonita aumenta sua superfície específica e sua porosidade, enquanto que diminui sua densidade..$^{18} \mathrm{O}$ incremento da superfície específica e da porosidade melhora a capacidade de adsorção das impurezas. No refino de óleos vegetais, o principal objetivo do uso de argilas ativadas com ácidos é a eliminação de uma série de contaminantes provenientes principalmente de organismos vegetai ${ }^{26}$ que dão cor e odor ao óleo, muitas vezes indesejáveis. Estudos recentes de ativação ácida das argilas bentoníticas da Península de Santa Elena, Equador, com soluções de $\mathrm{HCl}$ e $\mathrm{H}_{2} \mathrm{SO}_{4}$ a concentrações de 4,6 e $8 \mathrm{~mol} \mathrm{~L}^{-1}$ mostraram que a partir de $6 \mathrm{~mol} \mathrm{~L}^{-1}$ de $\mathrm{H}_{2} \mathrm{SO}_{4}$ se obteve aumento de porosidade e superfície específica das amostras e, consequentemente, maior eficiência no descoloramento do óleo de soja. ${ }^{27} \mathrm{O}$ presente trabalho visa a utilização das mesmas amostras naturais ${ }^{27}$ nos ensaios de pilarização com $\mathrm{Al}_{13}$ (cátion de Keggin), seguido de ativação ácida com $\mathrm{H}_{2} \mathrm{SO}_{4}$ e sua aplicação nos descoloramento de óleo de soja. Os resultados obtidos são comparados com os dados de ativação obtidos previamente, ${ }^{27}$ assim como com a eficiência de uma argila ativada comercial conhecida como Tonsil.

\section{PARTE EXPERIMENTAL}

\section{Amostras}

Duas amostras naturais, denominadas FT1 e FT8, provenientes de dois diferentes depósitos de argila da Península de Santa Elena, no Equador, foram utilizadas como material de partida para os ensaios de pilarização e ativação ácida. Estas amostras pertencem ao Membro Dos Bocas da Formação Tosagua. Esta formação, do Oligoceno ao Mioceno Inferior, possui uma espessura aproximada de 2000 m e é constituída principalmente por camadas centimétricas a decimétricas de argilitos de cor marrom, intercalados com finas camadas de gipsita e arenito..$^{28,29}$

\section{Ensaios de pilarização}

As duas amostras FT1 e FT8 foram pilarizadas segundo metodologia adaptada da literatura. ${ }^{30} \mathrm{O}$ agente pilarizante utilizado foi uma solução de alumínio preparada pela adição lenta de $\mathrm{NaOH}\left(0,2 \mathrm{~mol} \mathrm{~L}^{-1}\right)$ a uma solução de $\mathrm{AlCl}_{3} \cdot 6 \mathrm{H}_{2} \mathrm{O}\left(0,2 \mathrm{~mol} \mathrm{~L}^{-1}\right)$, sob agitação constante, até se obter uma relação molar de $[\mathrm{OH}] /[\mathrm{Al}]=2,0$. Esta solução foi envelhecida durante 6 dias, a temperatura ambiente.

As amostras foram tratadas com a solução pilarizante segundo a relação alumínio/argila de 10,15 e 20 meq g $^{-1}$, durante $2 \mathrm{~h}$ a temperatura ambiente $\left(298^{\circ} \mathrm{K}\right)$ e em agitação constante. A amostra seca, em forma de pó, foi adicionada lentamente à solução pilarizante, que esteve em cons- tante agitação. Os produtos obtidos foram lavados com água destilada até eliminar o excesso de cloreto. Após isto, foram centrifugados, secados a $333^{\circ} \mathrm{K}$, passados na peneira de 200 mesh e, finalmente, calcinados a temperaturas de 573,723 e $873^{\circ} \mathrm{K}$ durante $2 \mathrm{~h}$ e $30 \mathrm{~min}$. Para estas etapas de calcinação as amostras foram previamente aquecidas durante $30 \mathrm{~min}$ a $423^{\circ} \mathrm{K}$ para eliminar a água adsorvida.

\section{Ensaios de tratamento ácido}

As amostras naturais e as pilarizadas com 15 meq $\mathrm{Al} \mathrm{g}^{-1}$ de argila calcinadas a $573^{\circ} \mathrm{K}$ foram tratadas $\mathrm{com} \mathrm{H}_{2} \mathrm{SO}_{4}$ em concentrações de 4, $6 \mathrm{e}$ $8 \mathrm{~mol} \mathrm{~L}^{-1}$, a $358^{\circ} \mathrm{K}$, com a relação amostra/ácido de 1:10, durante $4 \mathrm{~h}$, em agitação constante com refluxo. ${ }^{21}$ Após o tratamento ácido, as amostras foram lavadas e decantadas durante $20 \mathrm{~min}$. As amostras foram secadas a $333{ }^{\circ} \mathrm{K}$, moídas e passadas em peneiras de 200 mesh $(0,075 \mathrm{~mm})$.

\section{Caracterização das amostras}

Nas amostras naturais foram quantificadas as três frações granulométricas de acordo com seus diâmetros esféricos médios $(\Phi)$ : areia (2000 $\mu \mathrm{m}<\Phi<53 \mu \mathrm{m})$, silte $\left(53 \mu \mathrm{m}<\Phi<2 \mu \mathrm{m}\right.$ e) e argila $(\Phi<2 \mu \mathrm{m}){ }^{31,32}$

Todos os procedimentos de caracterização descritos nas seções seguintes foram realizados nas amostras naturais, ativadas, pilarizadas e ativadas após pilarizadas e, também, na argila comercial utilizada como referência.

Os difratogramas de raios X (DRX) das amostras não orientadas foram obtidos em um difratômetro de marca Rigaku geigerflex D/MAX-B (com radiação monocromática $\mathrm{CuK} \alpha$ ), com faixa angular entre 2 e $70^{\circ}$, velocidade de leitura de $1,2^{\circ} \mathrm{min}^{-1}$ para a fração total (amostra natural) e, de 2 a $35^{\circ}$, com velocidade de leitura de $0,6^{\circ} \mathrm{min}^{-1}$ para a fração argila $(\Phi$ $<2 \mu \mathrm{m}$ ). Análises termodiferenciais (ATD) e termogravimétricas (ATG) foram realizadas entre 298 e $1373{ }^{\circ} \mathrm{K}$, sob atmosfera de nitrogênio com um equipamento de marca TA Instruments, SDT 2960 e com taxa de aquecimento de $293{ }^{\circ} \mathrm{K} \mathrm{min}{ }^{-1}$ usando alumina como material padrão.

As análises químicas dos elementos maiores e menores foram obtidas em um espectrofotômetro de raios X da Magi X equipado com o software SuperQ.

A densidade foi medida usando um Multipicnometer da Quantachrome com o gás hélio. As análises de superfície específica e porosidade pelo método de BET (Brunauer, Emmett e Teller) foram obtidas usando um analisador automático, Nova 1000 da Quantachrome com adsorção de $\mathrm{N}_{2}$, a $77^{\circ} \mathrm{K}$ e desgasificação a $333^{\circ} \mathrm{K}$ durante $5 \mathrm{~h}$, tanto nas amostras naturais quanto nas calcinadas, a fim de manter os mesmos parâmetros.

\section{Ensaios de descoloramento do óleo}

Óleo de soja, fornecido pela empresa La Fabril S.A. de Guaiaquil, Equador, foi usado nos ensaios de descoloramento. O processo de descoloramento foi realizado utilizando-se a relação amostra/óleo de 2/100, temperatura de $363 \pm 275^{\circ} \mathrm{K}$, tempo de contato de 30 min e em constante agitação. ${ }^{21} \mathrm{~A}$ seguir, a mistura quente de óleo e argila foi centrifugada e decantada. O óleo foi armazenado em recipientes adequados para as análises de absorbância no espectrofotômetro de UV-visível.

Para os ensaios de descoloramento foram utilizadas as amostras FT1 e FT8 naturais, as pilarizadas $\left(10 \mathrm{meq} \mathrm{g}^{-1}-723^{\circ} \mathrm{K}\right.$ e $15 \mathrm{meq} \mathrm{g}^{-1}-573$ ${ }^{\circ} \mathrm{K}$ ), as ativadas e as ativadas após pilarizadas. A eficiência das amostras equatorianas no descoloramento do óleo de soja foi comparada com a argila comercial Tonsil, que é utilizada nos processos de refino de óleos pela empresa La Fabril S.A..

\section{Determinação da capacidade de descoloramento}

A capacidade das amostras de descolorir o óleo de soja foi medida 
usando um espectrofotômetro HP 450-x UV-visível com lâmpada de tungstênio. Água destilada foi usada como branco para as medidas de absorbância dos comprimentos de onda da clorofila contida no óleo, entre 600 e $700 \mathrm{~nm}$. Para as absorbâncias do $\beta$-caroteno contido no óleo os comprimentos de onda foram entre 300 e $500 \mathrm{~nm}$. Utilizou-se hexano como branco, em uma diluição de $80 \%$ de hexano com $20 \%$ de óleo. Esta porcentagem de óleo foi usada nos casos de óleo natural, óleo descolorido com as amostras ativadas (naturais e pilarizadas) com $8 \mathrm{~mol}$ $\mathrm{L}^{-1} \mathrm{H}_{2} \mathrm{SO}_{4}$ e óleo descolorido com a argila comercial. Para as demais medidas de absorbância do $\beta$-caroteno, a diluição usada foi de $90 \%$ de hexano com $10 \%$ de óleo. ${ }^{33}$

A capacidade de descoloramento das amostras foi determinada através da seguinte equação: ${ }^{24}$

Capacidade de descoloramento $(\%)=\frac{\mathrm{A}_{\mathrm{o}}-\mathrm{A}}{\mathrm{A}_{\mathrm{o}}} \times 100$

onde, $\mathrm{A}_{\mathrm{o}}$ e A são as absorbâncias do óleo natural e descolorido, respectivamente, medidas na absorbância máxima do óleo natural a um comprimento de onda relacionado aos picos mais proeminentes. ${ }^{34}$ Assim, para o $\beta$-caroteno os picos foram a 421,445 e $473 \mathrm{~nm}$ e para a clorofila, a $670 \mathrm{~nm}$.

\section{RESULTADOS E DISCUSSÃO}

A Tabela 1 mostra a distribuição granulométrica das duas amostras naturais. A amostra FT1 apresenta a maior percentagem da fração argila (> 50\%), que foi de $44 \%$ para a amostra FT8. As altas percentagens de silte nas duas amostras são devidas à presença de aglomerados de partículas da fração argila. ${ }^{35}$

Os difratogramas de raios $\mathrm{X}$ das amostras orientadas (Figura 1) indicaram a presença de montmorilonita como argilomineral predominante, com um pico em torno de $16 \AA$. Observam-se também argilominerais de mica e caulinita. Minerais não argilosos - quartzo, feldspato - estão presentes nas duas amostras, assim como traços de gipsita e goethita. A calcita está presente na amostra FT8. Difratogramas obtidos na fração argila (não mostrados) indicaram ainda a presença destes mesmos minerais. As composições químicas das amostras naturais, FT1 e FT8 (Tabela 2), corroboram as análises mineralógicas.

Tabela 1. Distribuição granulométrica das duas amostras naturais

\begin{tabular}{lcccc}
\hline $\begin{array}{l}\text { Unidade } \\
\text { litológica }\end{array}$ & Amostra & $\begin{array}{c}\text { Argila } \\
(\%)\end{array}$ & $\begin{array}{c}\text { Silte } \\
(\%)\end{array}$ & $\begin{array}{c}\text { Areia } \\
(\%)\end{array}$ \\
\hline $\begin{array}{l}\text { Formação } \\
\text { Tosagua }\end{array}$ & FT1 & 51,11 & 47,36 & 1,53 \\
\hline
\end{tabular}

Ao comparar a mineralogia da argila comercial com as das amostras FT1 e FT8 pode-se verificar que são similares, porém, caulinita, quartzo, feldspato, calcita e gipsita das duas amostras estudadas aparecem na argila comercial somente como traços. A exceção é a presença de anidrita $\left(\mathrm{CaSO}_{4}\right)$ na argila comercial. A semelhança da mineralogia das amostras naturais com a argila ativada comercial permite prever o potencial que possuem as argilas equatorianas para aplicação no descoloramento de óleo.

Os difratogramas das duas amostras naturais indicaram a presença da montmorilonita cálcica com valores de espaçamento interplanar basal $\left(d_{001}\right)$ de 16,3 Å para FT1 e de 15,9 Å para FT8. Após pilarização, estes valores variam entre 15,9 até $19,0 \AA$. O aumento no valor $d$ evidencia que ocorreu a expansão da estrutura cristalina da montmorilonita devido à introdução do íon $\mathrm{Al}_{13}$. Após calcinação das amostras pilarizadas a 573 ${ }^{\circ} \mathrm{K}, d$ se reduz até $2,2 \AA$ do valor quando expandidas. $\mathrm{A} 723^{\circ} \mathrm{K}$ começa o

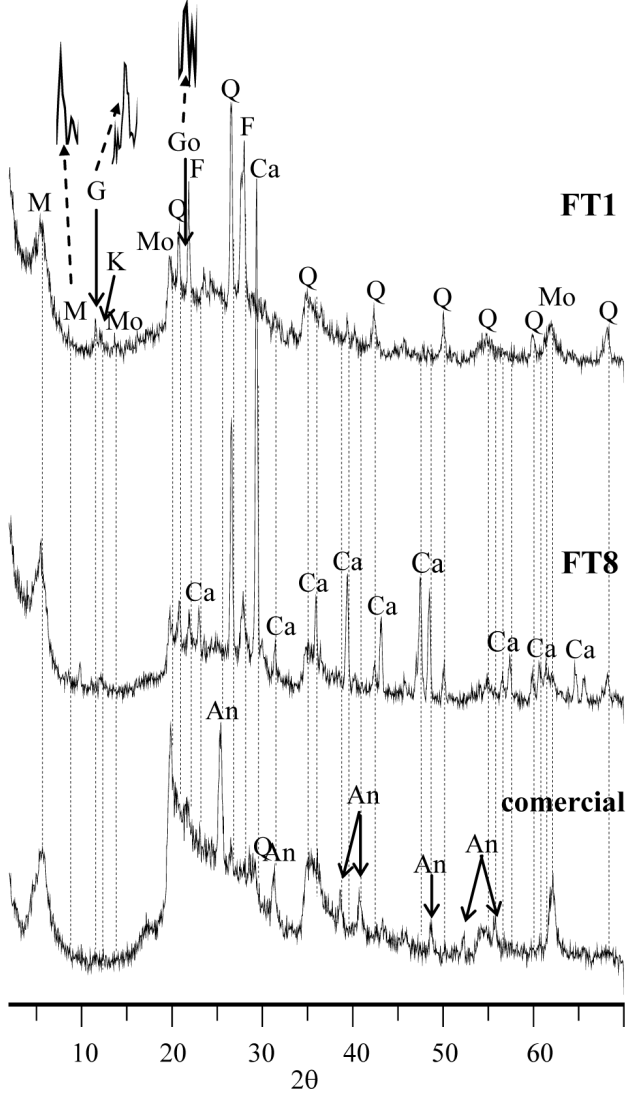

Figura 1. Difratogramas de raios $X(C u K \alpha)$ das amostras equatorianas naturais FT1 e FT8 e da argila comercial. Mo: montmorilonita, M: mica, G: gipsita K: caulinita, An: anidrita, Q: quartzo, Go: goethita, F: feldspato e Ca: calcita

colapso da estrutura cristalina da montmorilonita nas amostras pilarizadas com 15 e 20 meq de $\mathrm{Al} \mathrm{g}^{-1}$ de argila. Na maior parte das amostras calcinadas a $873{ }^{\circ} \mathrm{K}$ dificilmente é possível identificar picos, pois aparecem bandas onde existia o pico da montmorilonita, indicando que ocorreu o colapso total da sua estrutura cristalina. Na amostra FT1, a estabilidade térmica com 10 meq é até $723^{\circ} \mathrm{K}$ e com 15 e 20 é até $573^{\circ} \mathrm{K}$. Já para a FT8, todas são estáveis até $723^{\circ} \mathrm{K}$. De acordo com estes resultados mostrados nas Figuras 2 e 3, foram selecionadas as amostras pilarizadas com 10 e $15 \mathrm{meq} \mathrm{Al} \mathrm{g}^{-1}$ de argila, que foram calcinadas, respectivamente, a 723 e $573^{\circ} \mathrm{K}$. Estas amostras pilarizadas foram ativadas com 4, 6 e 8 mol L ${ }^{-1}$ de $\mathrm{H}_{2} \mathrm{SO}_{4}$. As características destas amostras pilarizadas e das pilarizadas e ativadas foram comparadas com as amostras naturais e com as ativadas com 4, 6 e 8 mol L ${ }^{-1} \mathrm{de}_{2} \mathrm{SO}_{4}{ }^{27}$ Os difratogramas da Figura 3 permitem observar a expansão e o colapso que ocorrem com a estrutura cristalina da montmorilonita, após os diferentes tratamentos de pilarização e ativação. ${ }^{27} \mathrm{~A}$ ativação ácida das amostras pilarizadas produz a destruição da estrutura cristalina da montmorilonita, portanto, ocorre o colapso desta estrutura. Um aumento da distância interplanar basal $\left(d_{o o l}\right)$ com a lixiviação com a solução $4 \mathrm{~mol} \mathrm{~L}^{-1}$ de ácido sulfúrico foi observado. Entretanto, com soluções de ácido mais concentradas não ocorreram alterações consideráveis nas distâncias interplanares $d_{001}$ nas amostras FT1. Na amostra FT8 ocorreu um aumento de 1,5 ̊̊ neste parâmetro. Assim, a eliminação dos agentes cimentantes parece ter contribuído para o enfraquecimento das interações intercamadas pela troca parcial dos cátions interlamelares, ocorrendo praticamente o colapso da estrutura da montmorilonita nas amostras ativadas com $8 \mathrm{~mol} \mathrm{~L}^{-1} \mathrm{H}_{2} \mathrm{SO}_{4}$.

Após pilarização das amostras FT1 e FT8 naturais, em geral, tevese um acréscimo de $\mathrm{Al}_{2} \mathrm{O}_{3}$ em relação às amostras naturais, os teores de $\mathrm{CaO}$ e $\mathrm{MgO}$ diminuíram em pouca proporção, enquanto que os outros 
Tabela 2. Composição química das amostras naturais, pilarizadas, pilarizadas e ativadas, ativadas e da argila comercial

\begin{tabular}{|c|c|c|c|c|c|c|c|c|c|c|}
\hline Ensaio & $\%$ Amostra* & $\mathrm{SiO}_{2}$ & $\mathrm{Al}_{2} \mathrm{O}_{3}$ & $\mathrm{Fe}_{2} \mathrm{O}_{3}$ & $\mathrm{MgO}$ & $\mathrm{CaO}$ & $\mathrm{K}_{2} \mathrm{O}$ & $\mathrm{Na}_{2} \mathrm{O}$ & $\mathrm{TiO}_{2}$ & P.F.** \\
\hline & FT1 & 52,93 & 17,05 & 7,35 & 1,90 & 2,07 & 1,47 & 1,18 & 0,76 & 14,93 \\
\hline \multirow{2}{*}{ Pilarização } & FT1 10-723 & 49,63 & 23,39 & 9,68 & 1,59 & 1,16 & 1,56 & 2,50 & 0,87 & 9,22 \\
\hline & FT1 15-573 & 50,33 & 23,98 & 9,28 & 1,61 & 1,00 & 1,64 & 1,63 & 0,88 & 9,31 \\
\hline \multirow{3}{*}{ Pilarização } & FT8 & 51,52 & 16,72 & 6,39 & 1,93 & 5,83 & 0,86 & 1,19 & 0,66 & 14,66 \\
\hline & FT8 10-723 & 49,63 & 26,51 & 7,01 & 1,51 & 3,59 & 0,91 & 2,72 & 0,76 & 7,09 \\
\hline & FT8 15-573 & 50,33 & 28,73 & 7,07 & 1,51 & 1,27 & 0,96 & 1,55 & 0,77 & 7,54 \\
\hline \multirow{6}{*}{$\begin{array}{l}\text { Pilarização e } \\
\text { Ativação Ácida }\end{array}$} & FT1 15-573 4AS & 55,06 & 22,83 & 2,79 & 0,51 & 0,99 & 0,57 & 0,53 & 1,14 & 15,55 \\
\hline & FT1 15-573 6AS & 57,70 & 22,22 & 2,31 & 0,61 & 0,94 & 0,59 & 0,84 & 1,17 & 13,60 \\
\hline & FT1 15-573 8AS & 58,21 & 21,63 & 2,23 & 0,52 & 0,93 & 0,59 & 0,96 & 1,00 & 13,91 \\
\hline & FT8 15-573 4AS & 54,84 & 25,38 & 1,82 & 0,62 & 0,82 & 0,49 & 0,93 & 0,99 & 14,08 \\
\hline & FT8 15-573 6AS & 59,01 & 22,80 & 1,44 & 0,61 & 0,81 & 0,56 & 0,97 & 0,88 & 12,9 \\
\hline & FT8 15-573 8AS & 60,58 & 21,99 & 1,10 & 0,52 & 0,74 & 0,54 & 0,92 & 0,87 & 12,72 \\
\hline \multirow{7}{*}{ Ativação Ácida } & FT1 4AS & 64,96 & 17,02 & 2,36 & 0,50 & 1,83 & 0,83 & $<0,10$ & 0,83 & 11,64 \\
\hline & FT1 6AS & 67,71 & 16,86 & 1,85 & 0,40 & 1,80 & 0,82 & $<0,10$ & 0,82 & 9,73 \\
\hline & FT1 8AS & 65,75 & 16,76 & 1,81 & 0,35 & 1,14 & 0,83 & $<0,10$ & 0,78 & 12,57 \\
\hline & FT8 4AS & 62,29 & 16,54 & 2,55 & 0,61 & 0,91 & 1,05 & $<0,10$ & 0,77 & 15,26 \\
\hline & FT8 6AS & 65,73 & 15,75 & 1,74 & 0,35 & 0,96 & 1,04 & $<0,10$ & 0,74 & 13,69 \\
\hline & FT8 8AS & 63,72 & 15,36 & 2,07 & 0,43 & 0,80 & 1,03 & $<0,10$ & 0,78 & 15,81 \\
\hline & comercial & 72,59 & 9,85 & 2,33 & 1,54 & 1,86 & 0,24 & 0,29 & 0,34 & 10,91 \\
\hline
\end{tabular}

*As amostras são identificadas de acordo com o seu nome (FT1 ou FT8), seguido da relação (10,15 ou 20) meq de Al g-1 de argila, da temperatura de calcinação $\left(573\right.$ ou $\left.723^{\circ} \mathrm{K}\right)$ e de AS para as amostras ativadas com ácido sulfúrico. **P.F.: perda ao fogo

óxidos tiveram pequenas variações nos seus teores (Tabela 2). Sendo que a solução pilarizante é formada também por sódio, os teores de $\mathrm{Na}_{2} \mathrm{O}$ tiveram um pequeno acréscimo e, possivelmente, também podem estar contidos nas intercamadas. $\mathrm{O}$ aumento de $\mathrm{Al}_{2} \mathrm{O}_{3}$ é compatível com o observado nos difratogramas de raios $\mathrm{X}$, isto é, houve a introdução do íon $\mathrm{Al}_{13}$ na estrutura cristalina da montmorilonita.

Reações de troca iônica de argilas montmoriloníticas com polioxicátions de alumínio (ou com outros reagentes pilarizantes) substituem os cátions ( $\mathrm{Na}, \mathrm{K}, \mathrm{Mg}, \mathrm{Ca})$ compensadores de cargas sem alterar o arranjo face-a-face das camadas de silicato. ${ }^{36}$ Isto parece que não ocorre completamente nas amostras equatorianas pilarizadas, como pode ser observado na Tabela 2, que não apresentam mudanças importantes nos teores dos óxidos de $\mathrm{Na}, \mathrm{K}, \mathrm{Mg}$ e $\mathrm{Ca}$ em relação às amostras naturais. Portanto, este fato deve ter influenciado negativamente em alguns casos em que a pilarização não ocorreu como se esperava; consequentemente, isto afetou os valores obtidos de densidade, superfície específica e porosidade. Comparando as amostras pilarizadas com as naturais, $\mathrm{SiO}_{2}$ decresce relativamente com a incorporação de $\mathrm{Al}_{13}$. Após ativação ácida este óxido é incrementado em todos os casos, em relação às amostras naturais e pilarizadas. Este incremento foi relativo à lixiviação dos outros óxidos.

Após ativação ácida das amostras pilarizadas, a composição química indica um importante decréscimo de $\mathrm{Fe}_{2} \mathrm{O}_{3}$, isto é, entre 62 e $70 \%$ na amostra FT1 e, entre 72 e $83 \%$ na amostra FT8, com o incremento da concentração do ácido. Os teores de $\mathrm{MgO}, \mathrm{K}_{2} \mathrm{O}, \mathrm{Na}_{2} \mathrm{O}, \mathrm{CaO}$ e $\mathrm{Al}_{2} \mathrm{O}_{3}$ também decresceram em relação às amostras pilarizadas, nessa ordem. ${ }^{18}$

Para os ensaios de ativação ácida, a Tabela 2 mostra que o ataque do material bentonítico com as soluções de ácido sulfúrico lixivia moderadamente o alumínio e esta lixiviação cresce suavemente quando a concentração do ácido cresce de 4 para $8 \mathrm{~mol} \mathrm{~L}^{-1}$. A lixiviação de $\mathrm{Fe}$, $\mathrm{Mg}, \mathrm{Ca}, \mathrm{K}$ e $\mathrm{Na}$ é extensa e proporcionalmente a quantidade de sílica cresce para satisfazer a condição percentual. Na amostra FT8 ativada, mais de $83 \%$ de $\mathrm{CaO}$ foi dissolvido, enquanto que, para a amostra FT1, a lixiviação foi menos eficiente.

A composição química da argila comercial mostrou elevada percentagem de $\mathrm{SiO}_{2}$ e menores percentagens de $\mathrm{K}_{2} \mathrm{O}$ e $\mathrm{TiO}_{2}$, quando comparadas com as amostras equatorianas ativadas. Essas variações podem refletir as diferenças mineralógicas observadas nos difratogramas indicados nas Figuras 1 e 3, como a presença de micas, feldspatos, nas amostras equatorianas.

As curvas termodiferenciais das amostras FT1 e FT8 naturais e pilarizadas (Figura 4) apresentam picos endotérmicos típicos da montmorilonita. Assim, os picos entre 326 e $538^{\circ} \mathrm{K}$ indicam a perda de água adsorvida na montmorilonita. Os picos entre 695 e $963{ }^{\circ} \mathrm{K}$ indicam a perda das hidroxilas da montmorilonita. ${ }^{37}$ Os picos em torno a $753{ }^{\circ} \mathrm{K}$ também representam a presença de caulinita. A montmorilonita com $\mathrm{Fe} e$ $\mathrm{Mg}$ substituindo $\mathrm{Al}$ no sítio octaédrico mostra um pico endotérmico entre 723 e $773{ }^{\circ} \mathrm{K}$ e outro, ao redor de $973{ }^{\circ} \mathrm{K} .{ }^{37} \mathrm{O}$ pico a $963^{\circ} \mathrm{K}$ na amostra FT8 indica a presença de carbonatos. ${ }^{38}$ Após os tratamentos de pilarização e ativação, em geral, não se observam maiores mudanças nestes picos, porém existem certos deslocamentos na posição dos picos. O pico dos carbonatos desaparece após esses tratamentos. A argila comercial também indica picos endotérmicos típicos da montmorilonita mais pura.

A Tabela 3 indica os valores de densidade, superfície específica e porosidade das amostras equatorianas, após ensaios de pilarização e ativação ácida, junto com os da argila comercial. Após pilarização das amostras FT1 e FT8 não aconteceram mudanças significativas na densidade, nem na porosidade, já a superfície específica diminui signi- 


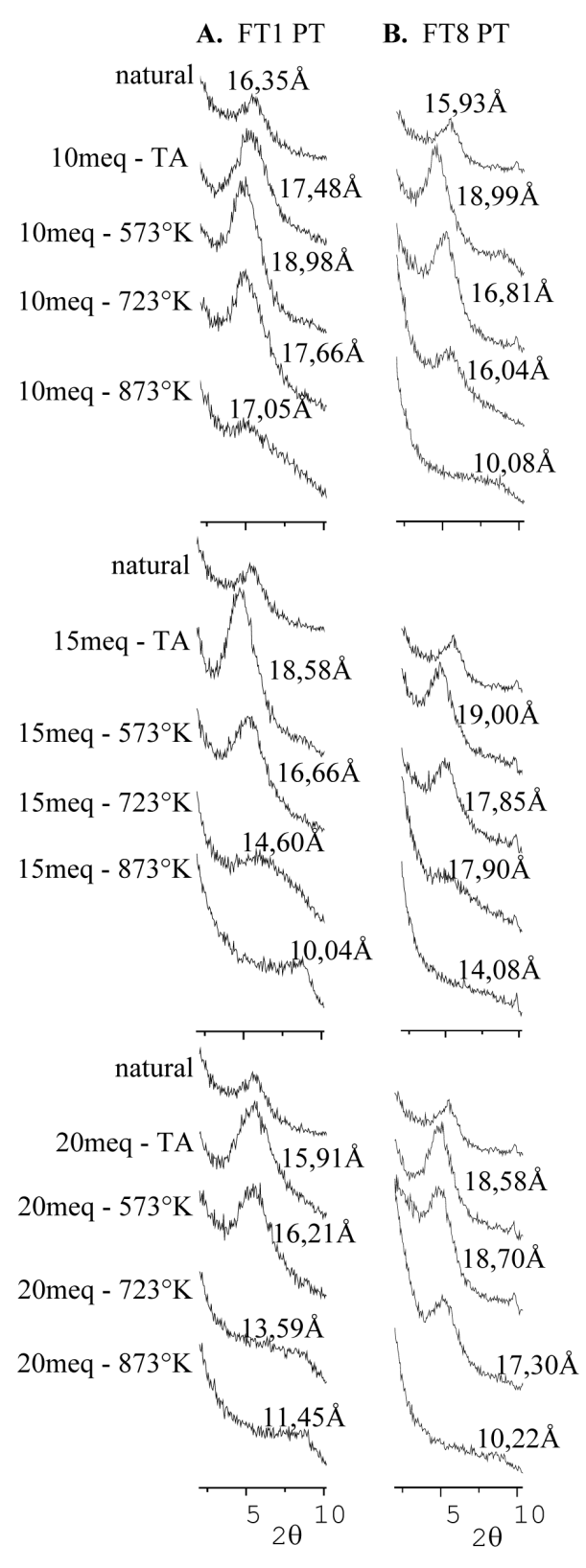

Figura 2. Mudanças na estrutura cristalina da montmorilonita das amostras FT1 e FT8, antes e após pilarização, segundo a variação meq de Al/g de argila e a temperatura. TA: temperatura ambiente

ficamente. Isto poderia estar relacionado com a não formação de pilares isolados, mas sim de aglomerados de modo a obliterar o espaçamento entre camadas, quando da adição das amostras secas e em forma de pó à solução pilarizante, resultando na pilarização deficiente, ou na não pilarização dessas amostras.

Visando obter acidez de Brönsted e maior reatividade no material, necessária para adsorção eficiente de cátions corantes, realizou-se o tratamento das argilas pilarizadas com soluções de ácido sulfúrico como realizado antes da intercalação. Após ativação destas mesmas amostras pilarizadas, a densidade diminuiu, enquanto aumentaram a superfície específica e a porosidade. O maior valor da amostra FT1 ativada com $4 \mathrm{~mol}$ $\mathrm{L}^{-1} \mathrm{de}_{2} \mathrm{SO}_{4}$ após pilarizada atingiu $85 \mathrm{~m}^{2} \mathrm{~g}^{-1}$. Já na amostra FT8 ativada com 6 e $8 \mathrm{~mol} \mathrm{~L}^{-1} \mathrm{de}_{2} \mathrm{SO}_{4}$ após pilarizada obtiveram-se valores de 111 e $122 \mathrm{~m}^{2} \mathrm{~g}^{-1}$, respectivamente, bem próximos da argila comercial, que é de $130 \mathrm{~m}^{2} \mathrm{~g}^{-1}$. É interessante observar que para a amostra FT1 o maior
A

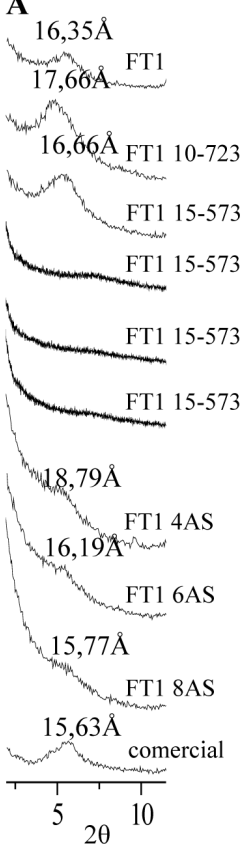

B

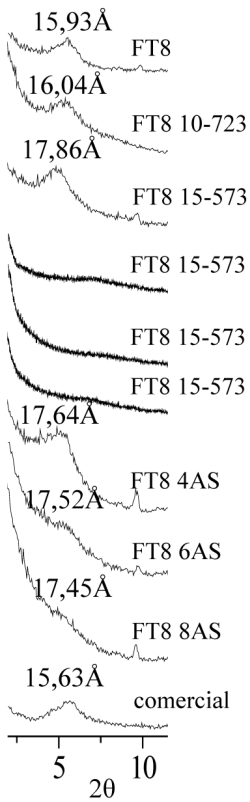

Figura 3. Modificações ocorridas na estrutura da montmorilonita nas amostras FT1 (A) e FT8 (B) após ensaios de pilarização e ativação ácida em relação às amostras naturais e a argila comercial

valor de área superficial foi obtido após tratamento com a solução ácida mais diluída. Já foi observado que esta área aumenta com a lixiviação ácida até um limite característico, que depende da argila tratada, e depois decresce com a intensificação do tratamento ácido. ${ }^{1}$ Para a amostra FT8 o aumento do volume de poros, da área superficial específica e consequente redução de densidade ocorreram quando a ativação ácida foi intensificada com o uso de soluções mais concentradas.

Nas amostras FT1 e FT8 ativadas com $\mathrm{H}_{2} \mathrm{SO}_{4}$, a densidade atingiu valores menores do que as amostras ativadas após pilarização, enquanto que os valores de porosidade são os maiores. Em relação à superfície específica, nas amostras ativadas os maiores valores foram obtidos com $8 \mathrm{~mol} \mathrm{~L}^{-1} \mathrm{de}_{2} \mathrm{SO}_{4}$, sendo de $100 \mathrm{~m}^{2} \mathrm{~g}^{-1}$ para FT1 e de $102 \mathrm{~m}^{2} \mathrm{~g}^{-1}$ para FT8. A limpeza da superfície dos cristais pelo ataque do ácido sulfúrico, devido à eliminação das impurezas orgânicas e inorgânicas desobstruiu os poros abertos, o que implica em aumento do volume de poros com consequente aumento do volume real, diminuição da densidade das partículas e aumento da área superficial específica como pode ser visto pelo comportamento geral dos dados tabelados.

A área superficial específica e o volume de poros apresentaram crescimento em geral quando soluções ácidas mais concentradas são usadas, entretanto o valor mínimo da área superficial específica de 120 $\mathrm{m}^{2} \mathrm{~g}^{-1}$ (determinada pelo método de BET), preconizada pela literatura não foi alcançada. ${ }^{26}$ Não existe diferença acentuada de comportamento das amostras naturais FT1 e FT8 frente às ativações ácidas.

Os resultados de descoloramento do óleo (Tabela 4), com as amostras naturais FT1 e FT8, mostram uma remoção de $\beta$-caroteno em torno de $12 \%$ e que nenhuma clorofila foi adsorvida. Para as amostras somente pilarizadas, estas apresentaram valores mais baixos do que $12 \%$ para o $\beta$-caroteno e nulos para clorofila. Na remoção de $\beta$-caroteno, as amostras ativadas com soluções 6 e $8 \mathrm{~mol} \mathrm{~L}^{-1} \mathrm{de}_{2} \mathrm{SO}_{4}$ atingiram os valores máximos entre 79 e $93 \%$ para FT1 e 75 e $86 \%$ para FT8. A clorofila foi removida mais eficientemente com as amostras ativadas com solução $6 \mathrm{~mol} \mathrm{~L}^{-1}$ de $\mathrm{H}_{2} \mathrm{SO}_{4}$, resultando em remoção de $82 \%$ para FT1 e $77 \%$ para FT8. Entretanto, com as amostras ativadas após pilarizadas foram atingidos valores de remoção de $\beta$-caroteno entre 39 e $92 \%$ e entre 46 

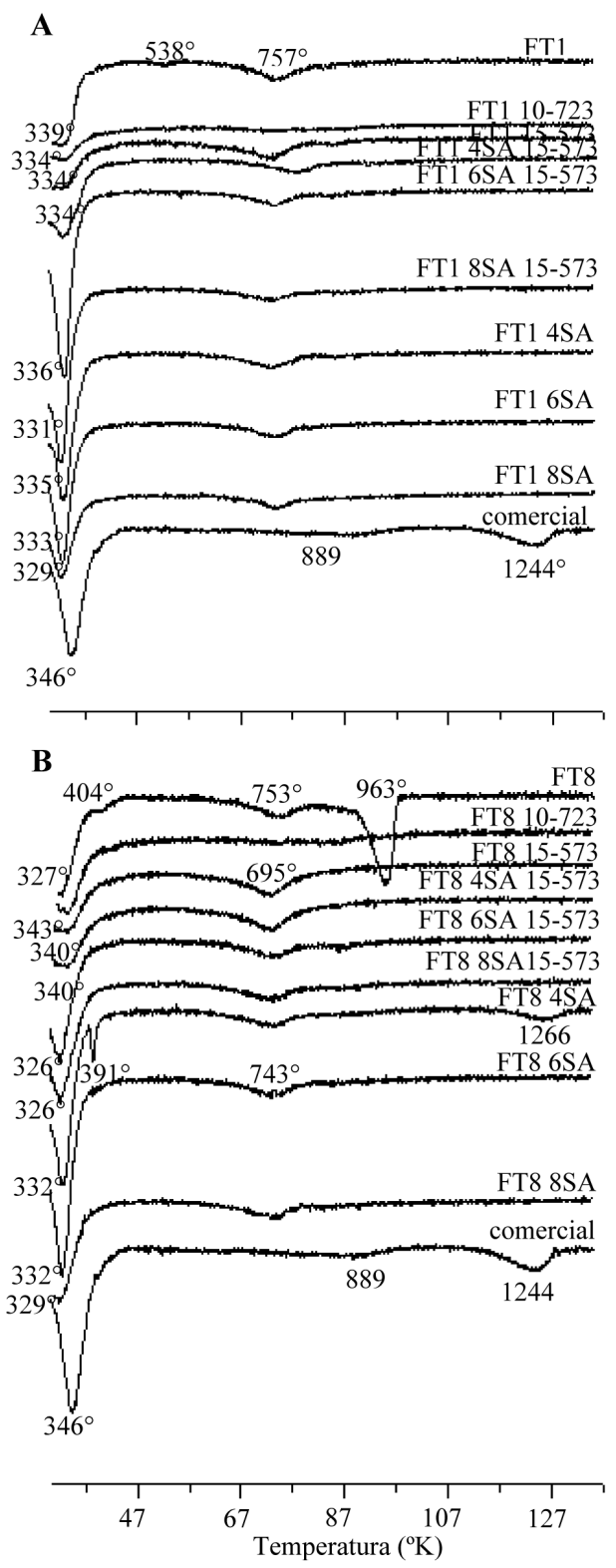

Figura 4. Curvas termodiferenciais (DTA) para as amostras FT1 (A) e FT8 (B), naturais, pilarizadas, pilarizadas e ativadas, ativadas e para argila comercial

e $88 \%$ para a clorofila, porém nas amostras pilarizadas com 15 meq a $573{ }^{\circ} \mathrm{K}$ e logo ativadas com solução $8 \mathrm{~mol} \mathrm{~L}^{-1} \mathrm{de}_{2} \mathrm{SO}_{4}$ se atingiram os maiores valores. Assim, na remoção de $\beta$-caroteno obtiveram-se valores entre 78 e $86 \%$ com FT 115 meq g $^{-1}-573^{\circ} \mathrm{K}$ solução 8 mol L $^{-1}$ de $_{2} \mathrm{SO}_{4} \mathrm{e}$ entre 84 e $92 \%$ com FT8 15 meq g ${ }^{-1}-573$ K solução 8 mol L $^{-1}$ de $_{2} \mathrm{SO}_{4}$. Na remoção da clorofila, obteve-se $88 \%$ com ambas amostras.

Os valores de descoloramento da argila comercial para o caroteno e a clorofila são similares aos obtidos com as amostras ativadas, porém um pouco menores que os obtidos com as amostras ativadas após pilarizadas.

\section{CONCLUSÕES}

As duas amostras equatorianas de argilas bentoníticas, FT1 e FT8, que foram submetidas aos ensaios de pilarização e ativação ácida mostraram os mesmos resultados quando foi avaliado seu potencial no descoloramento de óleo vegetal.

A pilarização destas duas amostras resultou em um aumento do espaçamento interplanar basal devido à introdução do íon $\mathrm{Al}_{13}$ na
Tabela 3. Valores de densidade, superfície específica e volume total de poros para as amostras FT1 e FT8 naturais, pilarizadas, pilarizadas e ativadas e ativadas, e também para a argila comercial

\begin{tabular}{|c|c|c|c|c|}
\hline Ensaio & Amostra & $\begin{array}{c}\text { Densidade } \\
\left(\mathrm{g} \mathrm{cm}^{-3}\right)\end{array}$ & $\begin{array}{c}\text { Superfície } \\
\text { específica } \\
\left(\mathrm{m}^{2} \mathrm{~g}^{-1}\right)\end{array}$ & $\begin{array}{c}\text { Volume total } \\
\text { de poros } \\
\left(\mathrm{cm}^{3} \mathrm{~g}^{-1}\right)\end{array}$ \\
\hline & FT1 & 2,64 & 33,70 & 0,0482 \\
\hline \multirow{3}{*}{ Pilarização } & FT1 10-723 & 2,67 & 3,79 & 0,0197 \\
\hline & FT1 15-573 & 2,72 & 5,93 & 0,0301 \\
\hline & FT8 & 2,64 & 43,89 & 0,0407 \\
\hline \multirow{2}{*}{ Pilarização } & FT8 10-723 & 2,79 & 5,76 & 0,0404 \\
\hline & FT8 15-573 & 2,66 & 6,56 & 0,0383 \\
\hline \multirow{6}{*}{$\begin{array}{l}\text { Pilarização } \\
\text { e Ativação } \\
\text { Ácida }\end{array}$} & FT1 15-573 4AS & 2,41 & 85,36 & 0,1056 \\
\hline & FT1 15-573 6AS & 2,32 & 52,05 & 0,0919 \\
\hline & FT1 15-573 8AS & 2,23 & 50,46 & 0,1075 \\
\hline & FT8 15-573 4AS & 2,34 & 16,08 & 0,0306 \\
\hline & FT8 15-573 6AS & 2,48 & 110,80 & 0,1931 \\
\hline & FT8 15-573 8AS & 2,45 & 122,20 & 0,1834 \\
\hline \multirow{7}{*}{$\begin{array}{l}\text { Ativação } \\
\text { Ácida }\end{array}$} & FT1 4AS & 2,13 & 56,82 & 0,0979 \\
\hline & FT1 6AS & 2,29 & 79,71 & 0,1621 \\
\hline & FT1 8AS & 2,45 & 99,72 & 0,1891 \\
\hline & FT8 4AS & 2,14 & 39,84 & 0,0713 \\
\hline & FT8 6AS & 2,16 & 69,25 & 0,1205 \\
\hline & FT8 8AS & 2,23 & 102,40 & 0,1705 \\
\hline & Comercial & 2,17 & 129,80 & 0,0288 \\
\hline
\end{tabular}

estrutura cristalina da montmorilonita, porém, os valores de superfície específica e de porosidade diminuíram. Estes resultados sugerem que não ocorreu a formação de pilares, mas sim de aglomerados quando da adição das amostras, secas e em forma de pó, à solução pilarizante, portanto não houve a completa troca dos íons intercamada pelo $\mathrm{Al}_{13}$. Para ambas as amostras, a estabilidade térmica máxima permaneceu até $723^{\circ} \mathrm{K}$ e a maior incorporação do íon $\mathrm{Al}_{13}$ foi obtida com a relação 15 meq de $\mathrm{Al} \mathrm{g}^{-1}$ de argila.

Por outro lado, após ativação ácida das amostras pilarizadas e das naturais houve incremento nos valores de superfície específica e da porosidade.

A aplicação das amostras naturais, das pilarizadas e das ativadas no descoloramento do óleo de soja mostrou que as ativadas com $8 \mathrm{~mol} \mathrm{~L}^{-1}$ de $\mathrm{H}_{2} \mathrm{SO}_{4}$ logo após serem pilarizadas com $15 \mathrm{meq}$ de $\mathrm{Al} \mathrm{g}{ }^{-1}$ de argila e calcinadas a $573{ }^{\circ} \mathrm{K}$ foram as mais eficientes na remoção dos pigmentos $\beta$-caroteno e clorofila contidos no óleo de soja, inclusive do que a argila comercial. Porém, as amostras ativadas com 6 e $8 \mathrm{~mol} \mathrm{~L}^{-1}$ de $\mathrm{H}_{2} \mathrm{SO}_{4}$ a partir de amostras naturais também foram eficientes no descoloramento do óleo de soja. Estes resultados indicam que a eficiência das amostras no descoloramento está relacionada com a ativação ácida e, portanto, com o incremento da superfície específica e da porosidade.

A maior remoção dos corantes do óleo pelas amostras ativadas após pilarizadas pode ser atribuída aos sítios ácidos de Brönsted criados na superfície da alumina dos pilares, além daqueles originados da protonação dos cantos e faces dos cristalitos provenientes da ativação ácida após pilarização. 
Tabela 4. Capacidade de descoloramento do óleo de soja usando as amostras equatorianas naturais, pilarizadas, pilarizadas e ativadas e, ativadas, além da argila comercial, baseada na adsorção de $\beta$-caroteno e clorofila

Capacidade de descoloramento

Ensaio Amostra

$\beta$-caroteno clorofila $421 \mathrm{~nm} 445 \mathrm{~nm} 473 \mathrm{~nm} 670 \mathrm{~nm}$

\begin{tabular}{|c|c|c|c|c|c|}
\hline & FT1 & 12,47 & 12,56 & 12,78 & $-64,33$ \\
\hline \multirow{3}{*}{ Pilarização } & FT1 10-723 & 5,73 & 5,63 & 5,87 & $-92,01$ \\
\hline & FT1 15-573 & 9,31 & 10,54 & 11,41 & $-84,87$ \\
\hline & FT8 & 11,10 & 11,76 & 11,45 & $-68,05$ \\
\hline \multirow{2}{*}{ Pilarização } & FT8 10-723 & 3,59 & 3,07 & 3,32 & $-82,53$ \\
\hline & FT8 15-573 & 6,06 & 7,08 & 7,79 & $-81,36$ \\
\hline \multirow{12}{*}{$\begin{array}{l}\text { Pilarização } \\
\text { e Ativação } \\
\text { Ácida }\end{array}$} & FT1 10-723 4AS & 39,14 & 52,21 & 53,95 & 61,65 \\
\hline & FT1 10-723 6AS & 59,99 & 71,92 & 74,14 & 75,14 \\
\hline & FT1 10-723 8AS & 76,76 & 83,74 & 86,20 & 79,55 \\
\hline & FT8 10-723 4AS & 56,72 & 64,68 & 66,98 & 76,88 \\
\hline & FT8 10-723 6AS & 72,80 & 84,18 & 86,58 & 46,04 \\
\hline & FT8 10-723 8AS & 72,30 & 78,78 & 81,65 & 82,52 \\
\hline & FT1 15-573 4AS & 50,64 & 62,30 & 63,74 & 72,97 \\
\hline & FT1 15-573 6AS & 66,69 & 77,58 & 79,53 & 81,54 \\
\hline & FT1 15-573 8AS & 78,05 & 85,75 & 87,59 & 87,58 \\
\hline & FT8 15-573 4AS & 74,33 & 83,28 & 85,14 & 83,83 \\
\hline & FT8 15-573 6AS & 75,61 & 87,86 & 88,56 & 77,80 \\
\hline & FT8 15-573 8AS & 83,63 & 90,35 & 92,05 & 88,18 \\
\hline \multirow{7}{*}{ Ativação Ácida } & FT1 4AS & 35,63 & 38,06 & 39,26 & $-0,76$ \\
\hline & FT1 6AS & 78,87 & 85,32 & 87,52 & 82,01 \\
\hline & FT1 8AS & 82,15 & 89,74 & 92,70 & 79,24 \\
\hline & FT8 4AS & 58,73 & 63,36 & 65,03 & 40,99 \\
\hline & FT8 6AS & 76,68 & 83,22 & 85,81 & 76,68 \\
\hline & FT8 8AS & 74,90 & 80,76 & 83,36 & 73,79 \\
\hline & Comercial & 80,66 & 87,69 & 89,43 & 83,82 \\
\hline
\end{tabular}

O comportamento das argilas bentoníticas frente às modificações estruturais pelos tratamentos de lixiviação ou ativação ácida, intercalação e pilarização não é simples e dificilmente podem ser feitas generalizações de tratamentos para qualquer bentonita. As respostas aos tratamentos dependem das quantidades e natureza dos argilominerais e dos contaminantes. Tratamentos devem ser estabelecidos para cada lote de material específico com pouca generalização.

\section{AGRADECIMENTOS}

À contribuição financeira do CNPq (Conselho Nacional de Desenvolvimento Científico e Tecnológico) e à colaboração técnica dos laboratórios dos Departamentos de Geologia, Química e Metalurgia à Universidade Federal de Ouro Preto. Nossos agradecimentos também ao Centro de Investigación Científica y Tecnológica, à Facultad de Ingeniería en Ciencias de la Tierra e ao Componente 6 do Programa VLIR/ESPOL da Escuela Superior Politécnica del Litoral, do Equador, pela assistência nos trabalhos de campo e, finalmente, à Empresa La Fabril S. A. pelo fornecimento da argila comercial e do óleo de soja natural.

\section{REFERÊNCIAS}

1. Dombrowsky, T.; Henderson, J.; Clays for our Future, Book of Abstracts, Carleton University: Ottawa, 1997.

2. Falaras, P.; Lezou, F.; Seiragakis, G.; Petrakjs, D.; Clays Clay Miner. 2000, 48,549 .

3. Kloprogge, J. T.; J. Porous Mater. 1998, 5, 5.

4. Vaughan, D. E. W.; Lussier, R. J.; Magee, Jr. J. S.; US pat. 4,176,090 1979.

5. Landau, S. D.; Hinnenkamp, J. A.; US pat. 5,037,787 1991.

6. Lewis, R. M.; Ott, K. C.; Van Santen, R. A.; US pat. 4,510,257 1985.

7. Yang, R. T.; Cichanowicz, J. E.; US pat. 5,415,850 1995.

8. Sun Kou, M. R.; Mendioroz, S.; Guijarro, M. I.; Thermochim. Acta 1998, $323,145$.

9. Valverde, J. L.; Cañizares, P.; Sun Kou, M. R.; Molina, C. B.; Clays Clay Miner. 2000, 48, 424.

10. Guiu, G.; Gil, A.; Montes, M.; Grange, P.; J. Catal. 1997, 168, 450.

11. Issaadi, R.; Garin, F.; Chitour, C.; Catal. Today 2006, 113, 166.

12. Salerno, P.; Mendioroz, S.; Appl. Clay Sci. 2002, 22, 115.

13. Luna, F. J.; Schuchardt, U.; Quim. Nova 1999, $22,104$.

14. Occelli, M. L.; J. Mol. Catal. 1986, 35, 377.

15. Mokaya, R.; Jones, W.; Davies, M. E.; Whittle, M. E.; J. Solid State Chem. 1994, 111, 157.

16. Caglayan, M. O.; Kafa, S.; Yigit, N.; J. Am. Oil Chem. Soc. 2005, 82, 599.

17. Davies, M. E.; Whittle, M. E.; Jones, W.; Mokaya, R.; US pat. 5,486,499 1996.

18. Grim, R. E.; Applied Clay Mineralogy, McGraw-Hill Book Company Inc.: New York, 1962.

19. Prutzman, P. W.; US pat. 1,397,113 1921.

20. Wilson, S. W.; Mass, B.; US pat. 2,192,000 1940.

21. Christidis, G. E.; Kosiari, S.; Petavratzi, E. Em 2001. A Clay Odyssey; Dominguez, E. A.; Mas, G. R.; Cravero, F., eds.; Elvesier: Amsterdam, 2003, cap. 6 .

22. Foletto, E. L; Volzone, C.; Morgado, A. F.; Porto, L. M. Em ref. 21, cap. 6.

23. Foletto, E. L.; Volzone, C.; Morgado, A. F.; Porto, L. M.; Cerâmica 2001, 47, 208.

24. Foletto, E. L.; Volzone, C.; Morgado, A. F.; Porto, L. M.; Mater. Res. 2001, $4,211$.

25. Zhansheng, W.; Chun, L.; Xifang, S.; Xiaolin, X.; Bin. D.; Jin'e, L.; Hongsheng, Z.; Chin. J. Chem. Eng. 2006, 14, 253.

26. Díaz, F. R. V.; Santos P. S.; Quim. Nova 2001, 24, 345.

27. Morales-Carrera, A. M.; Varajão, A. F. D. C.; Gonçalves, M. A.; Anais do $9^{\text {th }}$ International Congress for Applied Mineralogy, Brisbane, Austrália, 2008.

28. Bristow, C. R.; Hoffstetter, R.; Feininger; Hall, M. T.; Léxico Estratigráfico del Ecuador, $2^{\text {nd }}$ ed., Centre National de la Recherche Scientifique: Paris, 1977.

29. Del Arco, E. N.; Dugas, F.; Labrouse, B.; Anais do III Congreso Ecuatoriano de Ingenieros Geólogos, de Minas y Petróleos, Guaiaquil, Equador, 1983.

30. Pergher, S. B. C.; Corma, A.; Fornes, V.; Quim. Nova 1999, 22, 649.

31. Claessen, M. E. C.; Barreto, W. O.; Paula, S. L.; Duarte, M. N.; Manual de Métodos de Análises de Solo, $2^{\mathrm{a}}$ ed., EMBRAPA-CNPS: Rio de Janeiro, 1997.

32. Mato, L. F.; Neto, O. P. C.; Preda, W. N.; Relatório de Análise Granulométrica, Universidade Federal de Ouro Preto, Brasil, 1982.

33. Oliveira, C. G.; Dissertação de Mestrado, Universidade Federal de Santa Catarina, Brasil, 2001.

34. Ferri, M. G.; Fisiologia Vegetal, EDUSP: São Paulo, 1979.

35. Morales-Carrera, A. M.; Varajão, A. F. D. C.; Gonçalves, M. A.; Rev. Escola de Minas 2008 61, 95.

36. Occelli, M. L.; Catal. Today 1988, 2, 339.

37. Grim, R. E.; Clay Mineralogy, McGraw-Hill Book Company Inc.: New York, 1953.

38. Mackenzie, R. C.; The Differential Thermal Investigation of Clays, The Central Press: London, 1957. 